\title{
Associations Among Descriptors of Herd Management and Phenotypic and Genetic Levels of Health and Fertility
}

\author{
M. P. L. Calus, J. J. Windig, and R. F. Veerkamp \\ Animal Sciences Group, Division Animal Resources Development, \\ P.O. Box 65, 8200 AB Lelystad, The Netherlands
}

\begin{abstract}
The objective of this paper was to investigate the association of descriptors of herd environment with phenotypic levels and breeding values of fertility and health traits. Analyses were performed for 82,080 firstlactation heifers and 173,787 multiparous cows. Fourteen environmental parameters were defined that described herd environment, such as average protein production, average somatic cell score (SCS), average calving interval, and average body condition score (BCS). Herds with lower average SCS had, in general, more desirable values for almost all analyzed traits (i.e., days to first service was $7 \mathrm{~d}$ shorter), as did herds with lower average calving interval (i.e., 2.8\% lower incidence of predicted mastitis). Herds with higher average protein production had slightly poorer fertility but more desirable values for all other analyzed traits (i.e., $5.1 \%$ less predicted mastitis, 0.4 lower SCS, and 0.6 higher BCS). Variance components and breeding values of sires were estimated by applying a random regression on the environmental parameters. In general, genetic variances varied generally only slightly across environments. However, based on data exclusively for heifers, the genetic variance for number of inseminations was 4.1 times higher in herds with a higher number of inseminations, 1.9 times higher for survival in herds with higher fat to protein ratio, and 1.7 times higher for predicted mastitis in herds with higher number of inseminations. Based on the heifer data, the lowest estimated genetic correlation across environments was 0.76 (SE 0.21) for first-service conception between herds with differing average BCS. The minimum based on the cow data was 0.65 (SE 0.10 ) for survival between herds with differing average ages at calving. The relative importance of some fertility traits compared with yield traits doubled across environments. Possible reranking of individual animals within a population and the changes in genetic
\end{abstract}

Received January 18, 2005.

Accepted March 12, 2005.

Corresponding author: M. P. L. Calus; e-mail:mario.calus@wur.nl. variance across environments suggests that environment-specific breeding values should be estimated for use in customized selection indices.

(Key words: health and fertility traits, genotype-byenvironment interaction, environmental sensitivity, reaction norm model)

Abbreviation key: CIV = calving interval, DFS = days to first service, DFLS = days first to last service, DLS = days to last service, $\mathbf{E P}=$ environmental parameter, $\mathbf{E S}$ = environmental sensitivity of genetic variance, $\mathbf{F S C}=$ first-service conception, $\mathbf{N I N S}=$ number of inseminations per service period, NR56 = nonreturn at $56 \mathrm{~d}$ after first insemination.

\section{INTRODUCTION}

Possible options to compensate for the increasing fertility and health risks associated with selection for increased milk production (Emanuelson, 1988; Pryce et al., 1998; Rauw et al., 1998) are: 1) improvement of management such that the poorer genetic merit is alleviated, or 2) inclusion of health and fertility in genetic selection with sufficient weight to ensure there is no reduction of the genetic level for health and fertility (Philipsson et al., 1994). The extent to which these 2 options interact is often labeled as genotype-by-environment interaction, environmental sensitivity of genetic variance $(\mathbf{E S})$, or genetic variance in reaction norms. If the effects of genotype-by-environment interactions are important relative to the average effects of genotype and environment, ignoring management improvement might hinder the expression of the genetic improvement for health in poor environments. Alternatively, it could mean that observed genetic differences between animals are larger in poor health environments, and hence, there might be more benefit of genetic selection in these environments. Therefore, in the presence of ES, management and genetic improvement of health and fertility might support or counteract each other. Other consequences for genetic selection are that the relative importance of traits might change across environments, and thus the weights in total merit indexes (Namkoong, 1985), and 
that available EBV (theoretically most applicable to an average environment) might not be sufficient to select animals for specific environments. The consequences of ES for improvements in health and fertility due to reasons other than genetic selection might be that the expected response depends on the genetic background of the animals.

An interesting implication of ES is that selection on high phenotypic performance combined with a continually improving herd environment is expected to increase ES of the animals, as indicated in a simulation study (Kolmodin et al., 2003). Thus, in the long-term, improving management to alleviate the lower genetic level for health and fertility might result in a continuously smaller range of environments where animals maintain their health and fertility. This means that the expected increase in ES of the animals increases the importance of tuning genotype and environment. In the long-term, including existing ES in multitrait genetic selection might be necessary to enable specific selection of animals for a wide range of herd environments.

Studies about ES of health and fertility traits have used different methods, such as regression of health traits on pedigree indexes for production (Pryce et al., 1999), including a sire-by-herd interaction term in the statistical model for SCS (Samore et al., 2001), or estimating a genetic correlation for SCC between environments with a low or high within-herd standard deviation for milk yield (Castillo-Juarez et al., 2000; Raffrenato et al., 2003) or low or high herd-year average SCS (Banos and Shook, 1990). Those studies did not report significant ES. Reaction norm models including a genetic covariance function describing (co)variances over the range of environments (Kirkpatrick and Heckman, 1989) were applied for fertility traits in only a few studies, where heterogeneous heritabilities across fertility environments were reported (Distl, 2001; Kolmodin et al., 2002). Covariance functions enable us to include both heterogeneous genetic variances and genetic correlations as function of a continuous measure of the environment, avoiding the arbitrary grouping of environments, and might provide a better method to model ES.

The objective of this paper was to investigate the association of several descriptors of herd environment with 1) phenotypic levels of fertility and health, and 2) ES of breeding values for fertility and health obtained using a reaction norm model.

\section{MATERIALS AND METHODS}

\section{Test Day and Insemination Data}

Records for insemination and yields of milk, fat, and protein yield and SCC were available for 147,835 first- lactation heifers and 295,507 multiparous cows calving between July 1997 and June 1999. All animals were at least $75 \%$ Holstein-Friesian. Years were defined as July 1 through June 30, to ensure that the months with the most calvings fell in the middle of the defined year. First-lactation heifers were selected if they calved at an age between 640 and $1095 \mathrm{~d}$. Editing steps for environmental parameters (see below) reduced the number of heifers and cows to 116,727 and 230,887 , respectively. For heifers and cows separately, all (grand)daughters of (grand)sires with fewer than 20 (grand)daughters in the edited data were deleted, reducing the number of heifers to 87,375 and the number of cows to 192,615. Herd-year-season subgroups were formed based on the method of Crump et al. (1997) with a minimum of 5 animals per subclass, a minimum length of $30 \mathrm{~d}$, and a maximum length of $365 \mathrm{~d}$. Records of animals that could not be assigned to a group with at least 5 records or that were assigned to a group with fewer than 3 informative records for any of the traits were deleted. Additionally, (maternal grand)sires with progeny in fewer than 3 herd-yearseason classes, and herd-year-season classes with progeny of less than 3 (maternal grand)sires were deleted. The editing steps based on herd-year-season subclasses and offspring per sire were repeated until the final data set met all criteria, reducing the number of records of heifers to 82,080 and the number of records of cows to 173,787 . For the different traits, between 61,002 (calving interval) and 79,068 (SCS and predicted mastitis) records were informative for the heifer data, and between 118,818 (calving interval) and 167,031 (SCS and predicted mastitis) records were informative for the cow data.

\section{BCS Data}

Body condition scores were available for 76,811 heifers, of which 12,823 calved between July 7, 1997 and June 30, 1998, and 63,988 calved between July 1, 1998 and June 30, 1999. The BCS was scored by classifiers during herd classification. Records of animals scored after 305 DIM were deleted, reducing the number to 74,554 . Herd-year-season subclasses for BCS were defined as herd-visits of the classifiers. Animals in herdyear-season subclasses with fewer than 5 animals were deleted. These editing steps, combined with the criteria for environmental parameters (see below) reduced the number of records for BCS to 68,418 in 6184 herd-years. Heifers that calved in those herd-years and had a record for at least one of the other traits but no BCS records were included in the data with a missing value for BCS. This increased the number of records to 85,631 . Herd-year-season subgroups for all 
other traits were formed based on the method of Crump et al. (1997) with a minimum of 5 animals per subclass, a minimum length of $30 \mathrm{~d}$ and a maximum length of $365 \mathrm{~d}$. (Grand)daughters of (grand)sires with less than 10 (grand)daughters in the data were deleted. In total, 69,906 records were included for the analyses where BCS was included as trait or environmental parameter. For the different traits, between 50,653 (calving interval) and 66,923 (SCS and predicted mastitis) records were informative.

\section{Pedigree}

Initially all sires, paternal grand dams, and maternal grandsires of animals with records in the data were included in the pedigree file. All male predecessors of those animals, available from the pedigree data, were included. Identification of dams of bulls was included if a dam had 2 or more sons; otherwise, dams were included as base parents. For the heifers, 1754 (2361 for BCS) animals were included in the relationship matrix. For the cows, 3442 animals were included in the relationship matrix.

\section{Traits}

Fertility traits. Seven fertility traits were considered: days to first service (DFS), days to last service (DLS), days first to last service (DFLS), calving interval (CIV), number of inseminations per service period (NINS), first-service conception (FSC), and nonreturn at $56 \mathrm{~d}$ after first insemination (NR56). The DFS was calculated as the interval from calving to first service, DLS as interval from calving to last service, and DFLS as interval from first to last service. The CIV was the interval between 2 consecutive calvings. The NINS was the number of inseminations per service period. The FSC was 1 if the cow had only one insemination and a known next calving date, and 0 otherwise. The NR56 was 1 if within $56 \mathrm{~d}$ after the first insemination no second insemination was recorded and 0 otherwise.

Records for any of the traits were missing if no information was available to calculate the value for the trait. Records for DFS were considered missing if DFS was smaller than 20 or greater than 300 . Records for DLS were missing if DLS was smaller than 20 or greater than 500. Records for DFLS were missing if DFLS was greater than 400 . The NINS was missing if NINS was 0 or greater than 10. Records for CIV were missing for animals without a known next calving date, or if CIV was smaller than 300 or greater than 800 . These criteria were applied to exclude extremely long lactation records, records with extreme short gestations due to abortions, or records with errors.
Survival. Survival was defined following Pool et al. (2003), being 1 for cows with known next calving date. Survival was coded as 0 for cows without a known next calving date and with the latest test-day record occurring at least $140 \mathrm{~d}$ before the last recorded test day for the respective herd, as it was unlikely that a cow was still on the farm when no test-day records have been recorded in a period of $140 \mathrm{~d}$. Survival of animals was missing in all other situations.

SCS and predicted mastitis. Somatic cell score was defined as the average SCS across test days. A binary trait, called predicted mastitis, was used as indicator trait for mastitis following De Haas et al. (2004), being 1 if SCC on at least one test day during the lactation was greater than 400,000 cells $/ \mathrm{mL}$ and 0 otherwise.

BCS. Body condition score was measured on a scale from 1 to 9 [thin to fat; based on Lowman et al. (1976)]. An average BCS curve across test days was fitted with a smoothing spline (Gilmour et al., 2002) based on all available records. The deviance from the average BCS curve across DIM was used for the analyses.

\section{Environmental Parameters}

Fourteen environmental parameters (EP), describing herd management, were calculated as an average from all animals that had information on the characteristic and calved in the same herd-year. The EP were herd-year averages of protein production, fat-to-protein ratio, SCS, persistency, relative peak milk yield, age at calving, number of animals, change in the number of animals between consecutive herd-years, change in fat percentage between 14 and 77 DIM, calving interval, number of inseminations, peak calving date, distribution of calving dates, and BCS. For each individual $\mathrm{EP}$, all available information was included and at least 25 animals in a herd-year needed to be informative for the characteristic. For average BCS and $\mathrm{CIV}$, this criterion was, respectively, 5 and 10 animals, to prevent loss of great numbers of animals. For the same reason, no restriction was put on the EP average CIV in the BCS data. The EP were chosen because they represented management and herd environment, being, for instance, indicators for of herd-year levels of production, energy balance, and fertility. More detailed reasoning behind the selection of applied EP, grouping of EP, and full description of the calculation of these EP is given by Calus and Veerkamp (2003).

\section{Estimation of Mean Phenotypic Performance Across Environments}

To estimate the relationship between the mean phenotypic performance of the animals for the considered 
traits and the values of the EP, a model was used that corrected for possible systematic effects influencing the mean phenotypic performance. The model included fixed linear and quadratic regressions for age at calving and breed, and the relationship between the mean phenotypic performance and the EP was modeled with a 10th-order polynomial regression on EP. The same fixed effects were included in the model to estimate ES (for details see below). The relative change in mean phenotypic performance $(\Delta \mathrm{mpp})$ across environments was calculated as $\Delta \mathrm{mpp}=[(\mathrm{mpp} 90 \mathrm{th}-\mathrm{mpp} 10 \mathrm{th}) /$ mpp50th] $\times 100 \%$, where mpp10th, mpp50th, and mpp90th are mean phenotypic performances at 10th, $50 \mathrm{th}$, and 90th percentiles of the data ordered on increasing values of the analyzed EP.

\section{Estimation of Variance Components and Environmental Sensitivity}

Variance components were estimated separately for first-lactation heifers and multiparous cows with a sire-maternal grandsire model. Fixed effects were included in the model for mean, parity (only for the multiparous cows), and herd-year-season subclass. Fixed regressions were included to account for age at calving and for breed of the cow. A 10th-order fixed polynomial regression on EP was included, to account for the average effect across EP. The ES was modeled by applying a random regression for each (maternal grand)sire, representing its EBV, on values of an EP for the herdyears in which its (grand)daughters were producing. The incidence matrix of maternal grandsire effects was laid over the matrix of sire effects, i.e., if a bull had both entries in the data as sire and maternal grandsire, the breeding value as maternal grandsire was equal to half the breeding value as a sire. A random permanent environmental effect was included for the multiparous cows. The residual variance was estimated separately for 5 equally sized groups, based on increasing EP, to include heterogeneous residual variances in the model.

The applied model was:

$$
\begin{aligned}
Y_{k l m n o}=\mu & \text { FIXED EFFECTS }+\sum_{i=0}^{10} \beta_{\mathrm{i}} P_{\mathrm{ik}}+\sum_{j=0}^{s} \alpha_{\mathrm{jl}} P_{\mathrm{jk}} \\
& +1 / 2 * \sum_{j=0}^{s} \alpha_{\mathrm{jm}} P_{\mathrm{jk}}+\mathrm{pe}_{\mathrm{o}}+\mathrm{E}_{\mathrm{klmno}}
\end{aligned}
$$

where $Y_{k l m n o}$ is the performance of cow $o$; $\mu$ is the average performance over all animals; FIXED EFFECTS included herd-year-season subclasses, parity (only for the multiparous cows: $2,3,4+$ ), and second-order polynomial regressions on age at calving, and percentage of
Holstein Friesian, Dutch Friesian, and Meuse-RhineYssel genes; $\beta_{i}$ is coefficient $i$ of a fixed regression on element $i$ of the polynomials of all environments; $P_{i k}$ is element $i$ of the 10th-order polynomial of an environmental parameter of environment $k ; \alpha_{j l}$ is coefficient $j$ of the random regression on the orthogonal polynomials of all environmental parameters of the daughters of sire $l ; P_{j k}$ is element $j$ of the orthogonal polynomial resembling an environmental parameter of environment $k ; \alpha_{j m}$ is coefficient $j$ of the random regression on the orthogonal polynomials of all environments of the maternal granddaughters of sire $m$; $s$ is the largest significant estimable coefficient $j$ of the random regression for sire effects; $p e_{o}$ is a permanent environmental effect of cow $o$ (only for the multiparous cows for all traits except survival); and $E_{k l m n o}$ is the residual effect of cow $o$ in environment $k$ within group of environments $n(\mathrm{n}=1,2, \ldots, 5)$.

Definition of the genetic model resulted in estimated sire variances as a function of the values of the EP. Heritabilities were calculated as 4 times the sire variance divided by the sum of the residual variance (and the permanent environmental variance for the multiparous cows) and 1.25 times the sire variance. The factor 1.25 is explained by the fact that effects for both sires (1 times the sire variance) and maternal grand sires ( 0.25 times the sire variance) explained part of the genetic variance. All analyses were performed with ASREML (Gilmour et al., 2002). Residual covariances between groups of environments were assumed to be zero. All combinations of EP and traits were tested for the presence of ES, using the likelihood ratio test to identify the highest estimable significant order for the sire effect $(P<0.05)$. The test statistic was twice the difference in log likelihood between models with order $\mathrm{n}$ and $\mathrm{n}-1$, respectively.

\section{RESULTS}

\section{Environmental Parameters}

The mean, standard deviation, and range for the EP used in the analysis of the heifer data are given in Table 1. The values for the EP used for analysis of the higher parity cows were similar. Environmental parameters had correlations between -0.40 and 0.27 among each other, except for a correlation of 0.84 between average persistency and relative peak milk yield. This result indicated that herds with high persistency (as defined here) also tended to have a higher relative peak milk yield. Pairs of EP with the highest correlations were calculated from the same traits. 
Table 1. Mean, standard deviation, range, and values at 10th and 90th percentiles of the environmental parameters for the heifer data.

\begin{tabular}{lcccccc}
\hline $\begin{array}{l}\text { Environmental } \\
\text { parameter }\end{array}$ & Mean & SD & 10th & 90 th & Minimum & Maximum \\
\hline Protein (kg/305 d) & 289 & 27.0 & 256 & 323 & 167 & 408 \\
Fat/protein & 1.27 & 0.04 & 1.21 & 1.32 & 1.12 & 1.48 \\
SCS & 2.63 & 0.48 & 2.02 & 3.22 & 0.94 & 6.06 \\
Persistency & 1.54 & 0.12 & 1.40 & 1.69 & 1.15 & 2.35 \\
Relative peak milk yield & 1.40 & 0.04 & 1.35 & 1.46 & 1.27 & 1.73 \\
Age at calving (d) & 1370 & 134 & 1229 & 1580 & 947 & 1989 \\
Number of animals & 53.3 & 22.4 & 32 & 80 & 25 & 246 \\
Change number of animals & 3.2 & 9.0 & -7 & 13 & -49 & 57 \\
Change in fat percentage (\%) & -0.43 & 0.20 & -0.68 & -0.17 & -1.35 & 0.19 \\
Calving interval (d) & 392 & 16.9 & 373 & 412 & 345 & 527 \\
Number of inseminations & 2.07 & 0.35 & 1.68 & 2.52 & 1.18 & 4.28 \\
Peak calving date (d) & 149 & 56 & 81 & 205 & -10 & 414 \\
Distribution of calving dates & 0.35 & 0.10 & 0.24 & 0.48 & 0.00 & 0.93 \\
BCS (on 1-to-9 scale) & 4.35 & 0.70 & 3.46 & 5.22 & 1.46 & 7.44 \\
\hline
\end{tabular}

${ }^{1}$ The average difference in fat percentage on the test-day closest to 77 DIM and the test-day closest to 14 DIM.

${ }^{2}$ Years were defined from July 1 until June 30; d -10 means d 355 of the year before, d 414 means d 49 of the next year.

\section{Mean Phenotypic Performance Across Environments}

The relationship between the value of the EP and the mean phenotypic performance of traits is given by the estimated fixed polynomial regression on EP. The results are applicable for the "average" heifer in the data, being 0.9\% Meuse-Rhine-Yssel, 4.7\% Dutch Friesian, and $93.6 \%$ Holstein-Friesian, calving at an age of $791 \mathrm{~d}$. The relative change of the trait means from the 10th to the 90th percentile of the data (Table 2), for DFS, DLS, and DFLS were 8.3, 10.4, and 13.5\%
(7, 13, and $5 \mathrm{~d}$ ) respectively, with increasing average SCS. The NINS increased 4.7\% (0.09 inseminations) with increasing average protein production and number of animals, and decreased 4.1\% (0.09 inseminations) with increasing peak calving date. The FSC and NR56 decreased 4.0 and 6.9\%, respectively, (absolute decreases of 1.9 and $4.4 \%$ ) with increasing average protein production and number of animals, and increased 6.8 and $4.4 \%$, respectively, (absolute increases of 2.9 and $2.5 \%$ ) with increasing peak calving date. Survival and CIV did not have distinct associations

Table 2. The relative change in mean phenotypic performance ( $\Delta \mathrm{mpp}$ in $\%)$ from the 10th to the 90th percentile of the data, compared with the 50th percentile, as predicted by the 10th-order regression model. In the last row the means across all environments are given for each trait.

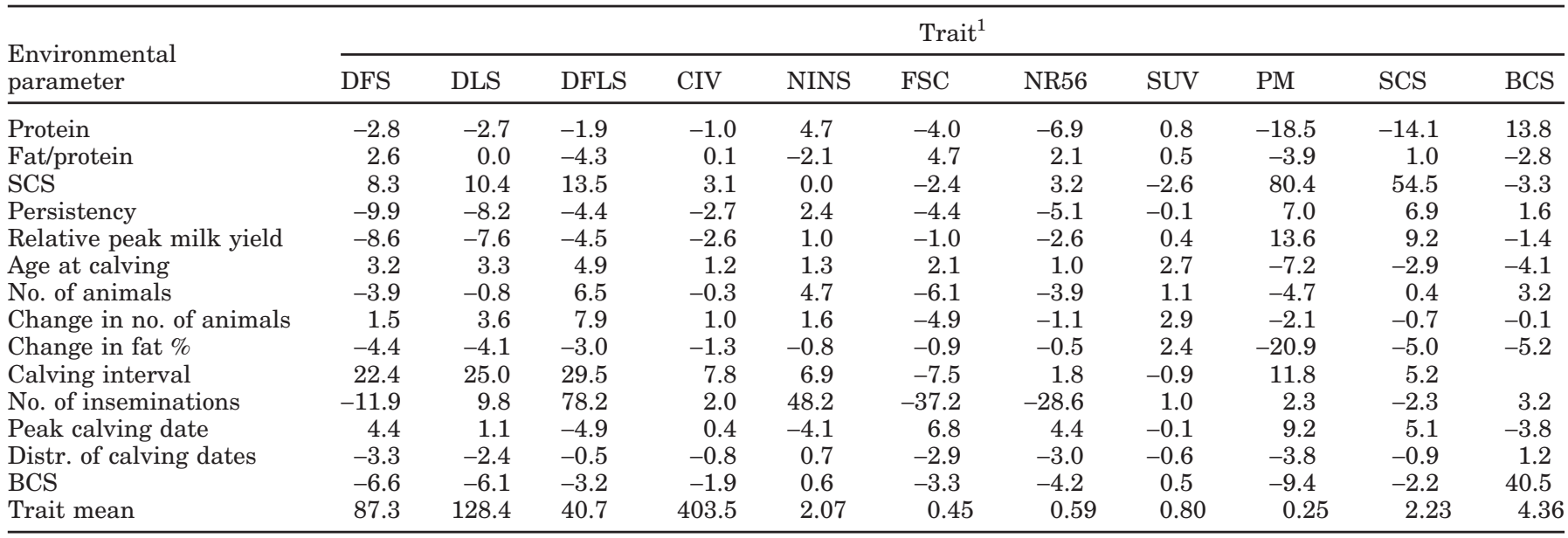

${ }^{1} \mathrm{DFS}=$ Days to first service, DLS = days to last service, DFLS = days first to last service, CIV = calving interval, NINS $=$ number of inseminations before conception, FSC = first service conception, NR56 = nonreturn at $56 \mathrm{~d}$, SUV = survival, PM = predicted mastitis based on test-day SCC, SCS = lactation average SCS. 
Table 3. Estimated genetic correlations ${ }^{1}$ between a trait expressed in the 10th and 90 th percentiles of the heifer data for all combinations of environmental parameters and traits with significant environmental sensitivity.

\begin{tabular}{|c|c|c|c|c|c|c|c|c|c|c|c|}
\hline \multirow{2}{*}{$\begin{array}{l}\text { Environmental } \\
\text { parameter }\end{array}$} & \multicolumn{11}{|c|}{ Trait $^{2}$} \\
\hline & DFS & DLS & DFLS & CIV & NINS & FSC & NR56 & SUV & PM & SCS & $\mathrm{BCS}$ \\
\hline Fat/protein & & & & & & & & 0.89 & 0.95 & & \\
\hline SCS & & & & & & & & & & 0.97 & \\
\hline Relative peak milk yield & & & & & & & & & & 1.00 & 0.99 \\
\hline Age at calving & & & & & & & & & & & 0.99 \\
\hline No. of animals & & & & & & & & & & & 0.97 \\
\hline Change in no. of animals & & & & & & & & 0.83 & & & 0.96 \\
\hline Change in fat $\%$ & 0.97 & & 0.99 & & & & & 0.84 & & & 0.98 \\
\hline Calving interval & 0.99 & 0.97 & & & & & & & & & \\
\hline No. of inseminations & & & 0.99 & & 0.96 & & & & 0.98 & & \\
\hline Peak calving date & & & & & & & & & 0.96 & & \\
\hline Distr. of calving dates & & & & & & & & & & & 1.00 \\
\hline BCS & 0.94 & & & & & 0.76 & & & & & 1.00 \\
\hline
\end{tabular}

\footnotetext{
${ }^{1}$ Standard errors of the genetic correlations ranged from 0.00 to 0.21 .

${ }^{2}$ DFS = Days to first service, DLS = days to last service, DFLS = days first to last service, $\mathrm{CIV}=$ calving interval, NINS = number of inseminations before conception, FSC $=$ first service conception, NR56 = nonreturn at $56 \mathrm{~d}, \mathrm{SUV}=$ survival, $\mathrm{PM}=$ predicted mastitis based on test-day $\mathrm{SCC}, \mathrm{SCS}$ = lactation average SCS.
}

with any of the EP. Incidence of predicted mastitis decreased $18.5 \%$ ( $-5.1 \%$ incidence) with increasing average protein production and $20.9 \%$ ( $-6.1 \%$ incidence) with increasing change in fat percentage and increased $13.6 \%(+3.2 \%$ incidence) with increasing relative peak milk yield and $11.8 \%$ ( $+2.8 \%$ incidence) with increasing calving interval. The SCS decreased $14.1 \%$ (0.4) and BCS increased 13.8\% (0.6) with increasing average protein production.

\section{Environmental Sensitivity}

Significant ES was estimated in 13.6 and $15.4 \%$ of all combinations of traits and EP for heifers and multiparous cows, respectively. Nearly all estimated ES was based on linear random regressions, but significant quadratic random regressions were fitted for the heifer data for survival combined with fat-to-protein ratio and change in fat percentage, and for the cow data for SCS combined with protein production. Of all combinations of EP and traits with significant ES based on the heifer data, estimated genetic correlations between the trait expressed in the 10th and 90th percentiles of the data ranged from 0.76 to 1.00 , but most were close to unity (Table 3 ). The lowest estimates were 0.76 (SE 0.21) for FSC combined with average BCS, 0.83 (SE 0.10) for survival combined with change of number of animals, and 0.84 (SE 0.12) for survival combined with change in fat percentage. Of all combinations of EP and traits with significant ES based on the cow data, estimated genetic correlations between the trait expressed in the 10th and 90th percentiles of the data ranged from 0.65 to 1.00 , but most were close to unity (Table 4). The lowest estimates were 0.65 (SE 0.10) for survival combined with average age at calving, 0.92 (SE 0.06) for DFLS combined with average SCS, and 0.92 (SE 0.05) for CIV combined with average protein.

The estimated genetic variances at the 10th and 90 th percentiles of the heifer data, as a ratio of the estimated genetic variance at the 50th percentile of the data, are given in Table 5 for all combinations of traits and EP with significant ES based on the heifer data. The genetic variance in the 90th percentile compared with the 10th percentile (of the heifer data) was, for instance, 4.1 times higher for NINS (EP = number of inseminations), 1.9 times higher for survival (EP = fat-to-protein ratio), and 1.7 times higher for predicted mastitis (EP = number of inseminations). This means that genetic variance of NINS was greater in herds with more inseminations, genetic variance of DFLS was greater in herds with more inseminations, genetic variance of survival was greater in herds with higher fat-to-protein ratio, and genetic variance of DLS was greater in herds with increased CIV. The genetic variances for the cow data increased up to 2 times between the 10th and 90th percentiles (results not shown).

In most cases, heritabilities changed little across environments. For the heifer data, heritabilities for DFS, DLS, DFLS, CIV, and NINS in the average environment were $0.09,0.06,0.03,0.05$, and 0.03 , respectively. Heritabilities for the binary traits FSC, NR56, survival, and predicted mastitis in the average environment were $0.01,0.01,0.03$, and 0.07 , respectively. The SCS and BCS had heritabilities in the average environment of 0.19 and 0.40 . The largest relative 
Table 4. The genetic correlations ${ }^{1}$ estimated on the cow data between 10 th and 90 th percentiles of the data for all combinations of environmental parameters and traits with significant genotype by environment interaction.

\begin{tabular}{|c|c|c|c|c|c|c|c|c|c|c|}
\hline \multirow{2}{*}{$\begin{array}{l}\text { Environmental } \\
\text { parameter }\end{array}$} & \multicolumn{10}{|c|}{ Trait $^{2}$} \\
\hline & DFS & DLS & DFLS & CIV & NINS & FSC & NR56 & SUV & PM & SCS \\
\hline Protein & & & & 0.92 & & & & 0.97 & 0.97 & 0.98 \\
\hline SCS & & & 0.92 & & & & & & 0.95 & 0.93 \\
\hline Age at calving & & & & & 0.93 & & & 0.65 & & \\
\hline No. of animals & & & & & & & & 0.98 & & \\
\hline Calving interval & 0.99 & 0.94 & & 0.93 & 0.99 & & & & & \\
\hline No. of inseminations & & 0.95 & 0.95 & 0.94 & 0.94 & & & & & 1.00 \\
\hline Distr. of calving dates & & & & & & 0.95 & & & & \\
\hline
\end{tabular}

${ }^{1}$ Standard errors of the genetic correlations ranged from 0.01 to 0.10 .

${ }^{2} \mathrm{DFS}=$ Days to first service, DLS = days to last service, DFLS = days first to last service, CIV = calving interval, NINS = number of inseminations before conception, FSC = first service conception, NR56 = nonreturn at $56 \mathrm{~d}, \mathrm{SUV}=$ survival, $\mathrm{PM}$ = predicted mastitis based on test-day SCC, SCS = lactation average SCS.

change in heritability was for the trait survival combined with the EP fat-to-protein ratio, being 0.025 in the 10th and 0.048 in the 90th percentile of the data.

Breeding values for survival for the 10 sires with most the daughters in the heifer data, estimated as function of herd-year average fat to protein ratio, followed different patterns across environments (Figure 1). The difference in survival of the first lactation of daughters of 2 particular sires (indicated with squares or triangles in Figure 1) was $+2.9 \%$ in herd environments with a fat-to-protein ratio of 1.19 and $-1.0 \%$ in herd environments with a fat-to-protein ratio of 1.33 .

\section{DISCUSSION}

The objective of this paper was to investigate associations among herd environment and fertility and health at both the phenotypic and genetic level. Herd average SCS and herd average CIV generally had a stronger association with average cow performance than did average protein production, indicating that other descriptors of herd management might be more important than production level per se. Although significant ES was only detected in a limited number of situations, the most extreme (i.e., the lowest) genetic correlation of a trait expressed in different environments was 0.7 , and genetic variance of some traits increased up to 4 times across environments. It is also important to note that the changes in genetic variance were in some situations in the opposite direction with respect to changes in genetic variance of production traits.

\section{Herd Characteristics Explaining Different Levels of Health and Fertility}

For the traits DFS, DLS, DFLS, CIV, NINS, predicted mastitis, and SCS, low values are desired, whereas high values are desired for the traits FSC, NR56, survival, and BCS. Lower herd averages for SCS and CIV were associated with more desirable average phenotypic values of almost all analyzed traits. A likely explanation might be that herds with lower SCS and shorter average CIV have on average better management, resulting in better overall fertility and health. This hypothesis is in agreement with results of Rougoor et al. (1999), who concluded that farmers that are aware of their bulk milk SCC and average CIV have better hygiene, lower feed costs, and higher milk price, resulting in a higher gross margin. Moreover, the results of Barkema et al. (1999) indicated that lower bulk milk SCC was associated with farmers that worked more precisely, paid more attention to individual cows, and made a greater effort to prevent mastitis.

Herds with higher average protein production had slightly lower success of insemination, but considerably less mastitis, lower SCS, and higher BCS. This result indicates that higher levels of production do not necessarily lead to poorer performance in other traits, possibly due to superior general management in those herds. The observation that heifers had less mastitis and lower SCS on farms with higher overall protein production seems to contradict reported positive within-herd phenotypic correlations between milk yield and mastitis (Ingvartsen et al., 2003). An explanation might be that herds with high production levels manage to control SCC on average, whereas within herds on an individual animal level, the animals with high production still have a higher chance to get mastitis, which is in agreement with the results of Windig et al. (2005). This result suggests that even though the average level of SCS of a herd can be influenced by management, an antagonistic relationship on an animal level might still exist between yield and SCS, 
thus indicating the need to investigate the extent to which phenotypic and genetic correlations between traits can be changed by herd management.

In herds with a high average number of inseminations, DFS was shorter and FSC and NR56 were lower, compared with herds with a low average number of inseminations. Average number of inseminations had correlations with average protein production and number of animals of 0.18 and 0.14 , respectively (results not shown). Herds with higher average protein production and higher number of animals also had, on average, shorter DFS and lower FSC and NR56. This trend indicates that the poorer success of first inseminations on herds with high average number of inseminations is not only explained by the stage of lactation in which insemination started, but also by the average protein production and the number of animals in the herd. Better insemination results in herds that start later with inseminating their cows, might be a result of the farmers' awareness of the poor response to early insemination, rather than better fertility per se.

\section{Interaction of Herd Characteristics and Breeding for Health and Fertility}

No particular EP was superior in terms of being associated with ES for most of the traits, but ES was more often detected in situations where the EP was the average of the analyzed trait or a characteristic closely related to the trait. Although these situations might be discarded as "only scaling effects" and therefore a purely statistical issue, the change in genetic variance across environments indicates the change in importance of selection for a certain trait across environments. In situations where the EP were calculated as the averages of the analyzed traits, the breeding values of the respective sires were included in the EP through the performance of their daughters. However, results from a simulation study showed that this fact does not lead to an overestimation of ES (Calus et al., 2004). Following the instruction from these authors, most EP were calculated from at least 25 animals and herd-year-season subclasses with daughters of fewer than 3 sires were deleted. This editing would thus have minimized the possible bias further.

Possible interactions between herd characteristics and breeding values for health and fertility traits were particularly notable for survival in both heifers and multiparous animals. In the heifer data, considerable changes in genetic variance were estimated for survival when herd environment was defined as fat-toprotein ratio, change in fat percentage, and change in number of animals, and the genetic correlations between survival expressed in different environments 


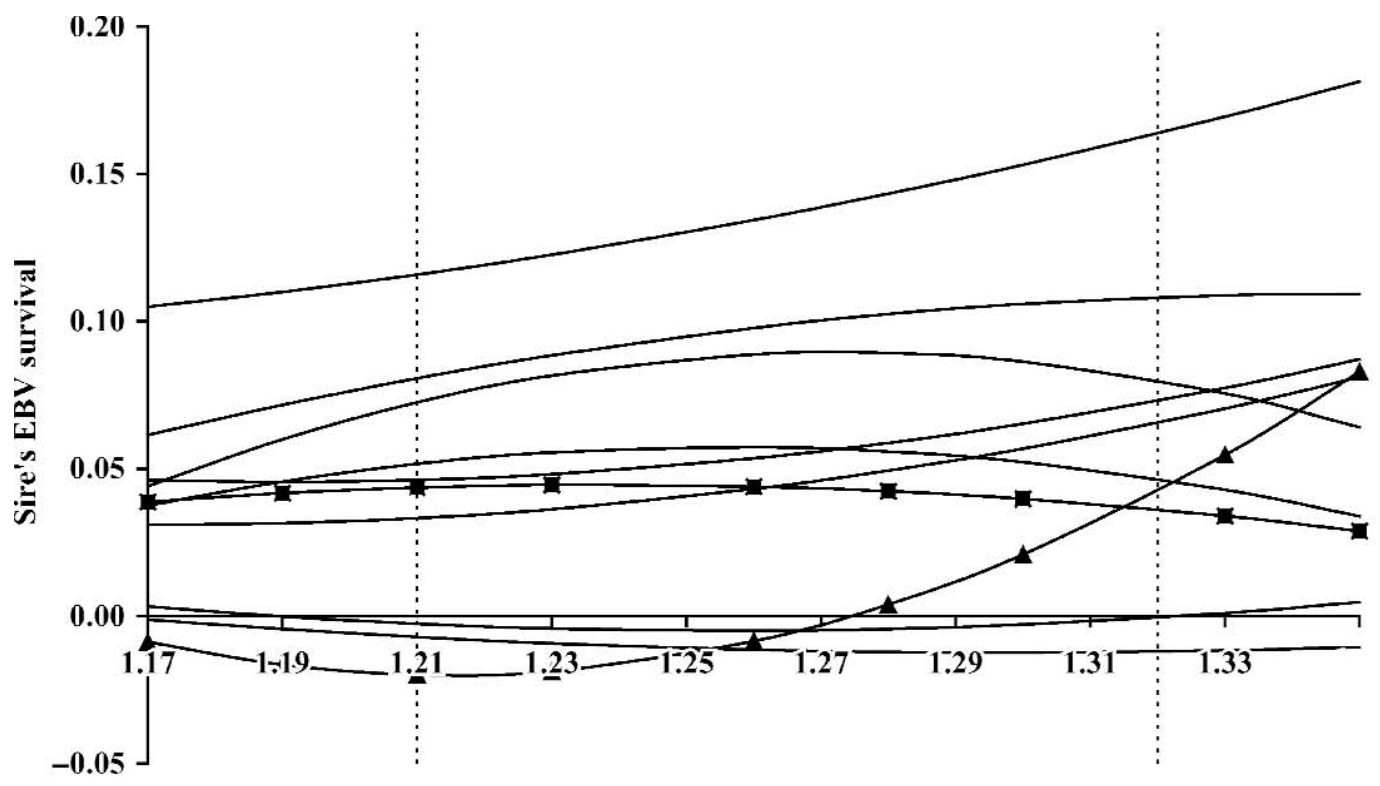

Herd-year average fat:protein ratio

Figure 1. Breeding values for survival of the 10 sires with most daughters in the heifer data, estimated as function of herd-year average fat-to-protein ratio (squares and triangles mark breeding values of 2 particular sires). Tenth and 90th percentiles of the data are shown as dotted lines.

were between 0.8 and 0.9 . Two of these EP are indicative of the nutritional environment; lower values for change in fat percentage are associated with longer lasting and more severe negative energy balance (De Vries and Veerkamp, 2000), and fat-to-protein ratio is influenced by the amount of concentrate and fiber in the diet (Bargo et al., 2003). Therefore, it might be hypothesized that reasons for culling heifers are different in herds with different diets, because a mismatch of genetic merit of the cows and diets results in increased health and fertility problems (Veerkamp et al., 1995) such as milk fever, days to first service, and days to first heat (Pryce et al., 1999). The third environmental parameter that gave significant ES for survival in heifers was change in the number of animals. This parameter might indicate whether the farm is shrinking or expanding, and the ES might possibly be caused by different culling reasons for heifers in herds that are either expanding or shrinking. In the data of multiparous cows, the genetic correlation between survival in herds with low vs. high average age at calving was 0.65 , indicating that cows in herds with a low average age at calving (and presumably an above average replacement rate) are culled for different reasons than in herds with high average age at calving. The implication of the ES for survival is demonstrated in Figure 1 for those sires that had the most daughters in the data set (i.e., relatively heavily used sires in the Netherlands). The sire marked with triangles had a higher EBV for survival in herds with high fat-toprotein ratio, whereas the EBV for survival of some other sires was hardly associated with the fat-to-protein ratio. These differences in patterns of the sires EBV indicate that at sire level ES has an important role, even though parameters at a population level indicate a more limited effect of ES. Nearly all genetic correlations were above 0.8 , which generally indicates that separate breeding programs for the extreme herd environments are not justified for an AI organization. However, considerable differences in the ranking of top bulls across environments might occur, even at genetic correlations between environments that are above 0.9 (e.g., Powell and VanRaden, 2002). To make use of the ES and reranking of individual genotypes, or reduce the chance of a mismatch between genotype and herd environment, herd-specific breeding values might be added to customized economic selection indices (Bowman et al., 1996) for selection of bulls on a herd level. Another strategy might be to select sires which are relatively environmental insensitive, i.e., to select against ES. Application of customized selection indexes would help to fine-tune genotype and environment, whereas selection against ES would actually decrease the need to fine-tune genotype and environment. 
Table 6. The change in relative importance to protein yield of yield traits and days to first service (DFS) across herd environments with different average calving intervals.

\begin{tabular}{lllll}
\hline \multirow{2}{*}{$\begin{array}{l}\text { Average calving } \\
\text { interval (d) }\end{array}$} & Milk & Fat & Protein & DFS \\
\cline { 2 - 5 } 350 & -0.47 & 0.21 & 1.00 & 0.06 \\
370 & -0.47 & 0.22 & 1.00 & 0.07 \\
390 & -0.46 & 0.22 & 1.00 & 0.09 \\
410 & -0.47 & 0.23 & 1.00 & 0.11 \\
430 & -0.48 & 0.23 & 1.00 & 0.12 \\
\hline
\end{tabular}

In addition to survival, changes in genetic variance across environments were observed for DFS and predicted mastitis in the heifer data. Genetic variance for DFS was larger for herds with a greater change in fat percentage, a larger CIV, and a lower BCS; hence, use of sires with desirable EBV for DFS is likely to be more beneficial in those herds. Genetic variance for predicted mastitis was higher in herds with lower fatto-protein ratio, higher number of inseminations, and earlier peak date of calving; thus, use of sires with desirable EBV for mastitis resistance is likely to be more beneficial in those herds. Changes in genetic variances of traits that are combined in a total merit index can cause reranking across environments based on the total merit index (Namkoong, 1985). The changes in genetic variances of the traits estimated on the heifer data were therefore compared with the estimated changes in genetic variances of milk, fat, and protein yield from a previous study (Calus and Veerkamp, 2003). Genetic variance of DFS increased $78 \%$ between 10th and 90th percentiles of the data based on increasing average calving interval, whereas genetic variance of milk, fat, and protein yield decreased 14,8 , and $15 \%$, respectively (Calus and Veerkamp, 2003). One way to express the relative importance of selection on a trait across environments is to multiply the economic value with the environment specific genetic standard deviation of the trait. Results for yield traits and DFS combined with EP average calving interval were calculated relative to the importance of protein yield per environment (Table 6). The economic values were $-0.08 €$ per $\mathrm{kg}$ of milk, $1 €$ per $\mathrm{kg}$ of fat, $6 €$ per $\mathrm{kg}$ of protein (NRS, 2001b), and 5.2 $€$ per standard deviation of the fertility index (NRS, 2001a). The economic value of the fertility index was used to calculate the economic value per unit of DFS, by dividing it by the genetic standard deviation in the average environment. The relative importance of DFS compared with protein yield was twice as high in a herd with an average calving interval of $430 \mathrm{~d}$, compared with a herd with an average calving interval of $370 \mathrm{~d}$ (Table 6). Hence, herd-specific breeding values

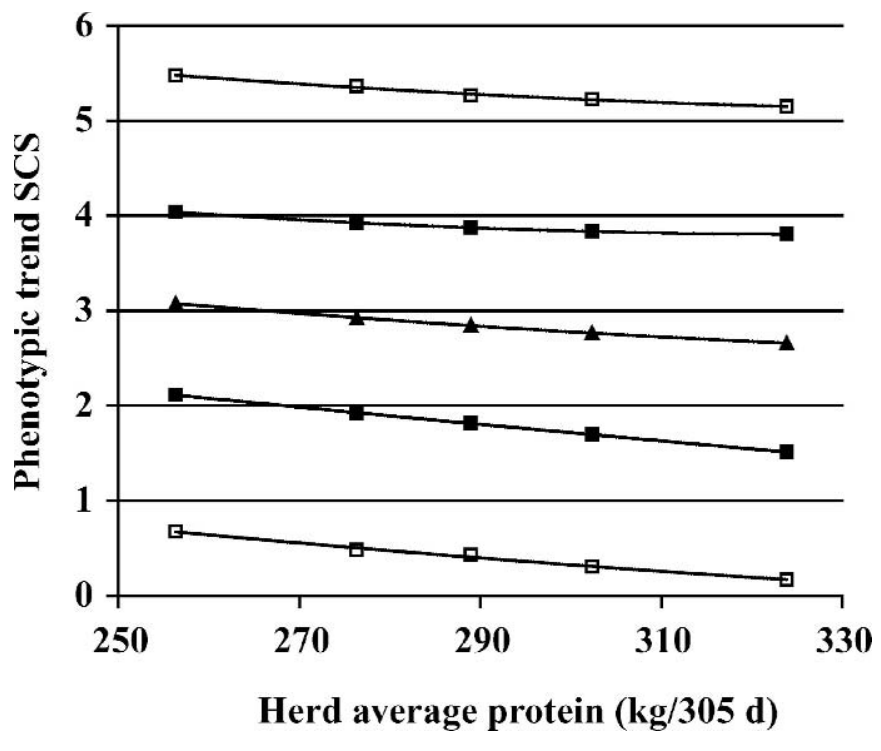

Figure 2. Phenotypic trend $(\boldsymbol{\Delta})$ of SCS \pm 2 times the genetic (ם) and phenotypic standard deviation ( $\square$ ) across herd average protein production estimated between 10th and 90th percentiles of the cow data.

in a customized index might be required to account for changes in the weighting of traits due to different changes in genetic variances of traits across environments.

\section{Health and Fertility Risks in Different Herd Environments}

Changes in management can influence average phenotypic performance, and, as demonstrated in this study, at the same time, the genetic and phenotypic variance. An interesting question is whether these changes go hand in hand, and if improvements in mean performance are sometimes offset by increase in variance that is so great that there is still an increase in the number of animals that perform below a threshold. In Figure 2, the mean phenotypic SCS \pm 2 times the genetic and phenotypic standard deviation is shown as function of average protein production. With increasing average protein production, mean SCS decreased, whereas the genetic variance of SCS increased slightly (Figure 2). Thus, the differences in SCS between progeny of different sires increase when protein production per cow per year increases. The phenotypic variance barely increased, however (Figure 2), and, combined with the improvement in phenotypic mean, the proportion of animals that have values for SCS above any particular value decreased with increasing average protein production. The same was true for other situations where an improvement in 
phenotypic mean was accompanied by an increase in variance, suggesting an improvement in phenotypic mean usually has more impact than an increase in variance.

\section{CONCLUSIONS}

Herd-year average SCS and herd-year average CIV had a stronger association with phenotypic levels of health and fertility traits than did production level per se. Somatic cell score and predicted mastitis were lower on average in herds with higher average protein production. Genetic correlations of traits expressed in different environments were mostly close to unity, but $<0.8$ in a few situations. Genetic variance was generally constant across environments, but doubled across the range of some environmental parameters, and the changes in genetic variance were in some situations in the opposite direction of the change in the mean of the production traits. The relative importance of some fertility traits compared with yield traits doubled across environments. Both reranking of individual animals within a population and the changes in genetic variances across environments suggest that environment-specific breeding values should be estimated that could be added to customized selection indices.

\section{ACKNOWLEDGMENTS}

This study was financially supported by the Ministry of Agriculture, Nature and Food Quality (Programme 414 "Maatschappelijk verantwoorde veehouderij"). The NRS is acknowledged for providing the data. The authors thank Johan van Arendonk and Piter Bijma for their suggestions and comments on the manuscript.

\section{REFERENCES}

Banos, G., and G. E. Shook. 1990. Genotype by environment interaction and genetic correlations among parities for somatic cell count and milk yield. J. Dairy Sci. 73:2563-2573.

Bargo, F., L. D. Muller, E. S. Kolver, and J. E. Delahoy. 2003. Invited Review: Production and digestion of supplemented dairy cows on pasture. J. Dairy Sci. 86:1-42.

Barkema, H. W., J. D. Van der Ploeg, Y. H. Schukken, T. J. G. M. Lam, G. Benedictus, and A. Brand. 1999. Management style and its association with bulk milk somatic cell count and incidence rate of clinical mastitis. J. Dairy Sci. 82:1655-1663.

Bowman, P. J., P. M. Visscher, and M. E. Goddard. 1996. Customized selection indices for dairy bulls in Australia. Anim. Sci. 62:393-403

Calus, M. P. L., P. Bijma, and R. F. Veerkamp. 2004. Effects of data structure on the estimation of covariance functions to describe genotype by environment interactions in a reaction norm model. Genet. Sel. Evol. 36:489-507.

Calus, M. P. L., and R. F. Veerkamp. 2003. Estimation of environmental sensitivity of genetic merit for milk production traits using a random regression model. J. Dairy Sci. 86:3756-3764.

Castillo-Juarez, H., P. A. Oltenacu, R. W. Blake, C. E. McCulloch, and E. G. Cienfuegos-Rivas. 2000. Effect of herd environment on the genetic and phenotypic relationships among milk yield, conception rate, and somatic cell score in Holstein cattle. J. Dairy Sci. 83:807-814.

Crump, R. E., N. R. Wray, R. Thompson, and G. Simm. 1997. Assigning pedigree beef performance records to contemporary groups taking account of within-herd calving patterns. Anim. Sci. 65:193-198.

De Haas, Y., R. F. Veerkamp, H. W. Barkema, Y. T. Gröhn, and Y. H. Schukken. 2004. Associations between pathogen-specific cases of clinical mastitis and somatic cell count patterns. J. Dairy Sci. 87:95-105.

De Vries, M. J., and R. F. Veerkamp. 2000. Energy balance of dairy cattle in relation to milk production variables and fertility. J. Dairy Sci. 83:62-69.

Distl, O. 2001. Implications of health traits in breeding of dairy cattle. Arch. Tierzucht 44:365-380.

Emanuelson, U. 1988. Recording of production diseases in cattle and possibilities for genetic improvements - A review. Livest. Prod. Sci. 20:89-106.

Gilmour, A. R., B. J. Gogel, B. R. Cullis, S. J. Welham, and R. Thompson. 2002. ASReml User Guide Release 1.0. VSN International Ltd., Hemel Hempstead, UK.

Ingvartsen, K. L., R. J. Dewhurst, and N. C. Friggens. 2003. On the relationship between lactational performance and health: Is it yield or metabolic imbalance that cause production diseases in dairy cattle? A position paper. Livest. Prod. Sci. 83:277-308.

Kirkpatrick, M., and N. Heckman. 1989. A quantitative genetic model for growth, shape, reaction norms, and other infinitedimensional characters. J. Math. Biol. 27:429-450.

Kolmodin, R., E. Strandberg, H. Jorjani, and B. Danell. 2003. Selection in the presence of a genotype by environment interaction: Response in environmental sensitivity. Anim. Sci. 76:375-385.

Kolmodin, R., E. Strandberg, P. Madsen, J. Jensen, and H. Jorjani. 2002. Genotype by environment interaction in Nordic dairy cattle studied using reaction norms. Acta Agric. Scand. A Anim. Sci. 52:11-24.

Lowman, B. G., N. A. Scott, and S. H. Sommerville. 1976. Condition scoring of cattle-Revised ed. Bull. No. 6. East of Scotland Coll. of Agric., Edinburgh, UK.

Namkoong, G. 1985. The influence of composite traits on genotype by environment relations. Theor. Appl. Genet. 70:315-317.

NRS. 2001a. Subject: E-17 Fokwaarde Vruchtbaarheid. https:// www.cr-delta.nl/crd-nrs/index.htm. Accessed Sep. 14, 2004.

NRS. 2001b. Subject: E-9 Index Netto Melkgeld (INET). https:// www.cr-delta.nl/crd-nrs/index.htm. Accessed Sep. 14, 2004.

Philipsson, J., G. Banos, and T. Arnason. 1994. Present and future uses of selection index methodology in dairy cattle. J. Dairy Sci. 77:3252-3261.

Pool, M. H., V. E. Olori, M. P. L. Calus, and R. F. Veerkamp. 2003. Aspects of milk yield adjustment in the parameter estimation for genetic evaluation of survival. Proc. Mtg. Int. Bull. Eval. Serv., Beltsville, MD. Interbull Centre, Uppsala, Sweden.

Powell, R. L., and P. M. Van Raden. 2002. International dairy bull evaluations expressed on national, subglobal, and global scales. J. Dairy Sci. 85:1863-1868.

Pryce, J. E., R. J. Esslemont, R. Thompson, R. F. Veerkamp, M. A. Kossaibati, and G. Simm. 1998. Estimation of genetic parameters using health, fertility and production data from a management recording system for dairy cattle. Anim. Sci. 66:577-584.

Pryce, J. E., B. L. Nielsen, R. F. Veerkamp, and G. Simm. 1999. Genotype and feeding system effects and interactions for health and fertility traits in dairy cattle. Livest. Prod. Sci. 57:193-201.

Raffrenato, E., R. W. Blake, P. A. Oltenacu, J. Carvalheira, and G. Licitra. 2003. Genotype by environment interaction for yield and somatic cell score with alternative environmental definitions. J. Dairy Sci. 86:2470-2479.

Rauw, W. M., E. Kanis, E. N. Noordhuizen-Stassen, and F. J. Grommers. 1998. Undesirable side effects of selection for high production efficiency in farm animals: A review. Livest. Prod. Sci. $56: 15-33$ 
Rougoor, C. W., W. J. A. Hanekamp, A. A. Dijkhuizen, M. Nielen, and J. B. M. Wilmink. 1999. Relationships between dairy cow mastitis and fertility management and farm performance. Prev. Vet. Med. 39:247-264.

Samore, A. B., J. A. M. Van Arendonk, and A. F. Groen. 2001. Impact of area and sire by herd interaction on heritability estimates for somatic cell count in Italian Holstein Friesian cows. J. Dairy Sci. 84:2555-2559.
Veerkamp, R. F., G. Simm, and J. D. Oldham. 1995. Genotype by environment interactions: Experience from Langhill. Pages 5966 in Breeding and Feeding the High Genetic Merit Dairy Cow. Br. Soc. Anim. Sci. Occas. Publ. 19. Br. Soc. Anim. Sci., Penicuik, UK.

Windig, J. J., M. P. L. Calus, and R. F. Veerkamp. 2005. Influence of herd environment on health and fertility and their relation with milk production. J. Dairy Sci. 88:335-347. 